\title{
In Vitro and Ex Vivo Effects of Silymarin Derivatives on Proinflammatory Cytokine Secretion Using a Murine Colonic Strip Model
}

()(1) $\odot \Theta$

\author{
Authors \\ Leo R. Fitzpatrick, Ella T. Mokrushin, George Talbott, Tibebe Woldermariam
}

\author{
Affiliation \\ Department of Pharmaceutical and Biomedical Sciences, \\ College of Pharmacy, California Northstate University, \\ Elk Grove, CA, USA \\ Key words \\ silymarin, silibinin, isosilibinin, anti-inflammatory, cytokines, \\ inflammatory bowel disease \\ received $\quad 02.07 .2018$ \\ revised $\quad 30.07 .2018$ \\ accepted 23.08.2018

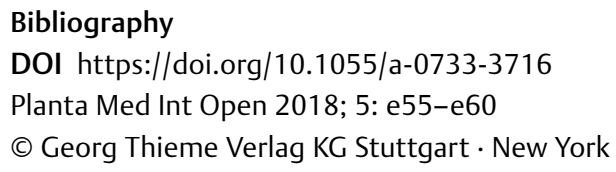

\begin{abstract}
Silymarin has anti-inflammatory properties and documented anti-colitis activity. Our prior study determined that in vitro treatment with certain extracted fractions of silymarin inhibited stimulated proinflammatory cytokine secretion from cell lines relevant to colitis. In this study, colitis was induced in mice by giving dextran sulfate sodium drinking water for 6 days. The ex vivo effects of crude silymarin extract, two different silymarin fractions, as well as commercially derived silibinin and isosilibinin were examined by determining the secretion of MIP-2, TNF- $\alpha$, and IL-17 in cell culture media from colonic strips. Further, the effects of silymarin-derived treatments on IL- 8 and TNF- $\alpha$ secretion induced by the colitis supernatant was characterized with HT-29 colonic epithelial and RAW 264.7 macrophage cell lines. Prominent inhibition of MIP-2 and TNF$\alpha$ secretion from colonic strips of mice with/without dextran sulfate sodium-induced colitis was observed with various silymarin treatments. Further, inhibition of dual (IL-23+IL-1 $\beta$ ) cytokine-stimulated secretion of IL-17 from colonic strips of mice was found with certain silymarin treatments. Significant attenuation of TNF- $\alpha$ secretion from colitis supernatant-stimulated RAW 264.7 cells was observed for crude silymarin extract and isosilibinin treatments. Finally, inhibition of IL-8 secretion from the colitis supernatant-stimulated HT29 colonic epithelial cell line was found with isosilibinin. These results contribute to the identification of silymarin-derived flavonoligans with optimal anti-inflammatory properties for further testing in colitis models.
\end{abstract}

\section{Introduction}

Inflammatory bowel disease (IBD) is a chronic inflammatory condition produced by a combination of genetic factors and changes in endogenous enteric bacteria. IBD is characterized by an abnormal immune response and chronic inflammation of the intestine. An increased production of cytokines, including TNF- $\alpha$, IL-1 $1 \beta$, IL-23, IL-6, IL-8, and IL-17 are associated with IBD. Thus, compounds with the capability to inhibit these cytokines can be utilized as potential drugs for IBD [1]. The current treatment approaches for IBD include antibiotics, corticosteroids, immunosuppressants, TNF- $\alpha$ monoclonal antibodies, and compounds containing mesalazine [1].

In an effort to discover novel bioactive natural plant products for the potential future treatment of IBD, we examined the silymarin complex for cytokine inhibition. The silymarin complex is an extract of milk thistle seeds comprised of four major classes of flavonolignans, including silibinin, silychristin, silydianin, and isosilibinin. The major and most active constituent of silymarin is historically considered to be silibinin $[2,3]$. These compounds are known for their antioxidant and anti-inflammatory properties [2]. 
Milk thistle (or silymarin) has been predominantly investigated in human clinical trials involving subjects with hepatitis or cirrhosis [4-6]. In addition, smaller studies were reported that included patients with acute lymphoblastic leukemia, prostate cancer, breast cancer, and hepatocellular carcinoma [7]. Of relevance to this paper, silymarin showed positive results in a small clinical trial utilizing patients with ulcerative colitis, a form of IBD [8].

Recently, we reported that silymarin derivatives inhibited proinflammatory cytokine secretion from macrophage and colonic epithelial cell lines [9]. As a follow-up to that basic cell culture study, the ex vivo effects of fractions/compounds derived from silymarin were examined for inhibiting cytokine secretion from colonic strips of mice with/without dextran sulfate sodium (DSS)-induced colitis. Further, the in vitro effects of these silymarin derivatives were studied in relevant cell lines stimulated by colonic supernatants from mice with colitis.

\section{Results}

Colon lengths are typically measured in conjunction with the murine DSS colitis model as an indicator of colonic damage [10]. As shown in > Table 1, treatment with DSS indeed significantly decreased the colon length as compared to the water treatment group. Disease activity indices (DAls) in DSS-treated mice are used as a "clinical" indicator of bloody stools, diarrhea, and body weight loss [10]. The mean DAI (on study day 6 ) was found to be significantly increased in DSS-treated mice as compared to that in watertreated animals ( $\triangleright$ Table $\mathbf{1}$ ). These results indicate that colitis was clearly established in our DSS-treated cohort of mice.

As suggested in > Fig. 1a, using colonic strips from DSS-treated mice, the mean percent inhibition of basal MIP-2 secretion (relative to vehicle treatment) was: Fraction $2(96 \%)=$ isosilibinin $(96 \%)>$ silibinin $(92 \%)>$ crude fraction $(75 \%)>$ fraction 5 (69\%). Significant reductions ( $p<0.05$ vs. vehicle/DSS) were obtained with all silymarin derivatives (at a concentration of $200 \mu \mathrm{g} / \mathrm{mL}$ ), although fraction 2 and isosilibinin were most effective. Silymarin fractions (as well as isosilibinin and silibinin) also reduced TNF- $\alpha$ secretion ( Fig. 1b). However, statistical significance compared to vehicle treatment was only attained by ex vivo treatment with fraction 2 and isosilibinin.

Using colonic strips from mice with colitis, silymarin derivatives also attenuated dual (IL-1 $\beta+$ IL-23) cytokine-induced colonic IL-17 secretion at concentrations in the range of $20-200 \mu \mathrm{g} / \mathrm{mL}$ ( $\mathbf{F i g . ~ 2 )}$. These derivatives demonstrated a dose-dependent inhibition pattern, with the exception of crude silymarin treatment. Significant inhibitions (at a concentration of $200 \mu \mathrm{g} / \mathrm{mL}$ ) were found with all silymarin-related treatment groups.

- Fig. 3 shows that ex vivo treatment with crude silymarin extract, two silymarin fractions, silibinin, and isosilibinin tended to also reduce dual cytokine-induced colonic IL-17 secretion from colonic strips of water-treated mice at concentrations in the range of $20-200 \mu \mathrm{g} / \mathrm{mL}$. However, significant reductions ( $p<0.05$ vs. vehicle/stimulated) were only obtained by ex vivo treatment with the crude extract $(200 \mu \mathrm{g} / \mathrm{mL})$ and isosilibinin $(100$ and $200 \mu \mathrm{g} / \mathrm{mL})$.

As illustrated in $\mathbf{F i g . ~ 4 a , ~ c r u d e ~ s i l y m a r i n ~ e x t r a c t , ~ i s o s i l i b i n i n , ~}$ and caffeic acid phenethyl ester (CAPE; positive control drug) sig- nificantly ( $p<0.05$ vs. vehicle + colitis supernatant) attenuated colitis supernatant (CS)-stimulated TNF- $\alpha$ secretion by RAW 264.7 cells. Cell viability (as determined by the MTT assay) showed no significant reductions in viability compared to the untreated control group ( $\triangleright$ Table 2 ). Therefore, the reductions in cytokine production by crude extract and/or isosilibinin cannot be accounted for by cellular toxicity.

Since isosilibinin was most effective for attenuating CS-induced cytokine secretion in the macrophage cell line, we also tested it for activity in a colonic epithelial cell line. $>$ Fig. $\mathbf{4 b}$ demonstrates that isosilibinin significantly attenuated CS-stimulated IL-8 secretion from HT29 cells ( $p<0.05$ vs. vehicle $+C S$ ). With this cell line, once

- Table 1 Parameters of DSS-induced colitis in mice (study day 6).

\begin{tabular}{|l|c|c|}
\hline $\begin{array}{l}\text { Treatment group } \\
\text { (number) }\end{array}$ & DAl (0-4 Scale) & Colon length (cm) \\
\hline Water $(n=8)$ & $0.1 \pm 0.1$ & $7.6 \pm 0.2^{*}$ \\
\hline DSS $(n=16)$ & $1.8 \pm 0.1$ & $6.4 \pm 0.2^{*}$ \\
\hline $\begin{array}{l}{ }^{*} \mathrm{P}<0.05 \text { vs. water (non-colitis mouse) control treatment group by } \\
\text { unpaired t-test analyses. }\end{array}$ \\
\hline
\end{tabular}

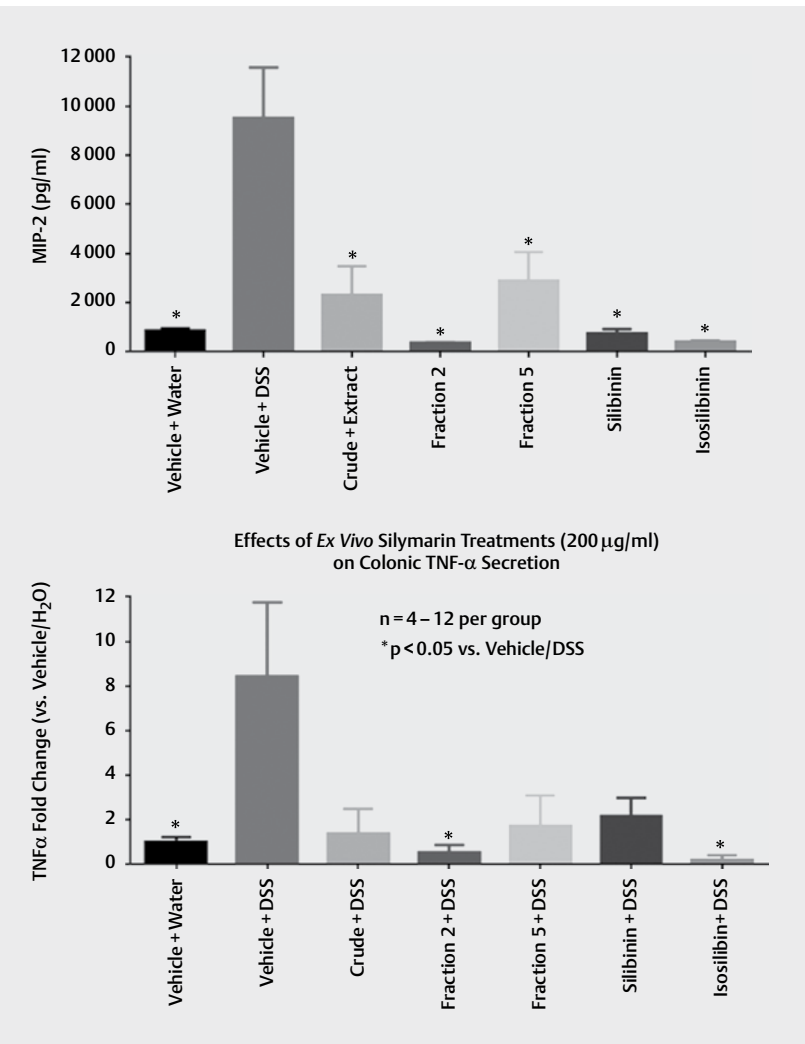

-Fig. 1 Effects of ex vivo treatment with silymarin crude extract, silymarin fractions 2 and 5, silibinin, and isosilibinin $(200 \mu \mathrm{g} / \mathrm{mL})$ on the increased colonic cytokine levels associated with colonic strips from mice with DSS-induced colitis. Cytokines were measured (after $24 \mathrm{~h}$ ) from colonic supernatants by specific ELISA kits for MIP-2 a and TNF- $\alpha$ b. The colonic cytokine contents are expressed as $\mathrm{pg} / \mathrm{mL}$ for MIP-2 and fold change for TNF- $\alpha$. Values represent the mean \pm SEM of $n=4-12$ per group ( $\mathrm{F}<0.05$ vs. vehicle/DSS in both panels in the figure). 
again, no significant reductions in viability were found compared to the untreated control group ( $\triangleright$ Table 2 ).

\section{Discussion}

Historically, the most active constituent of silymarin is considered to be silibinin [2,3]. Our previous study found that silibinin and isosilibinin containing fractions (numbers 2 and 5) of silymarin most potently inhibited proinflammatory cytokine secretion from macrophage and colonic epithelial cell lines [9]. Of note, fraction 2 contains predominantly isosilibin, while fraction 5 contains predominantly silibinin [9]. These cell culture system-derived results were the impetus for this study, which was to further characterize optimal in vitro and ex vivo anti-inflammatory/anti-colitis activities of silymarin-derived flavonoligans.

DSS induced colitis in mice is an established IBD model, which is commonly used for novel compound testing. IL-17, TNF- $\alpha$, and MIP-2 are upregulated in conjunction with this murine DSS colitis model $[10,11]$. In this regard, MIP-2 (a mouse equivalent to human IL-8) is chemotactic for neutrophils and induces localized colonic neutrophil infiltration associated with colitis [11]. Secretion of MIP-2 and TNF- $\alpha$ from colonic strips of mice with colitis were significantly attenuated by ex vivo treatment with silymarin derivatives, particularly fraction 2 (containing predominantly isosilibinin) and isosilibinin itself ( $\triangleright$ Fig. 1).

Kleinscheck et al. [12] reported increased levels of IL-17 secretion from lamina propria leuckocytes of patients with IBD upon stimulation with IL-23 and IL-1 $\beta$. Moreover, Coccia and colleagues [13] described the production of IL-17 from IL-1 $\beta$-stimulated innate lymphoid cells, and the synergistic effects of IL-23 and IL- $1 \beta$ on chronic intestinal inflammation. Furthermore, our laboratory previously described enhanced IL-17 secretion, by dual IL-23 and IL-1 $\beta$ stimulation, from colonic strips of mice with DSS-induced colitis [10]. This enhanced IL-17 secretion is dependent on the stimulation of NF-kB and STAT3 signal transduction pathways $[1,10]$. Recently, our laboratory showed that a documented anti-inflammatory/anti-colitis drug (GSK805) blocked IL-17 secretion from murine colonic strips $[14,15]$.

Using this colonic strip model system [10], our study shows that ex vivo treatment with various silymarin derivatives resulted in clear inhibition of dual cytokine-stimulated IL-17 secretion ( $>$ Fig. 2). Interestingly, treatment with fraction 2 and isosilibinin as well as silibinin was particularly effective for attenuating IL-17 secretion. In order to assess the effects of these flavonoligans on "physiological inflammation", we also determined their activities against dual cytokine-stimulated IL-17 secretion from colonic strips of mice without colitis. Once again, isosilibinin was particularly effective for blocking cytokine secretion ( $\triangleright$ Fig. 3 ).

Previously, our laboratory showed that gliotoxin and CAPE, two known NF-kB inhibitors, blocked cytokine production from macrophage and colonic epithelial cell lines $[16,17]$. Notably, gliotoxin inhibited CS-stimulated TNF- $\alpha$ secretion by macrophages [16]. Utilizing these previous experimental paradigms, we conducted similar types of experiments for this study. Initial dose-response experiments (data not shown) indicated that $50 \mu \mathrm{L}$ of CS was optimal for stimulating TNF- $\alpha$ secretion by macrophages. This amount of CS was used for subsequent experiments. Our results showed that isosilibinin $(200 \mu \mathrm{g} / \mathrm{mL})$ significantly inhibited CS-induced proinflammatory cytokine/chemokine secretion from two different cell lines ( $\triangleright$ Fig. 4) with relevance to the pathogenesis of colitis $[16,17]$.

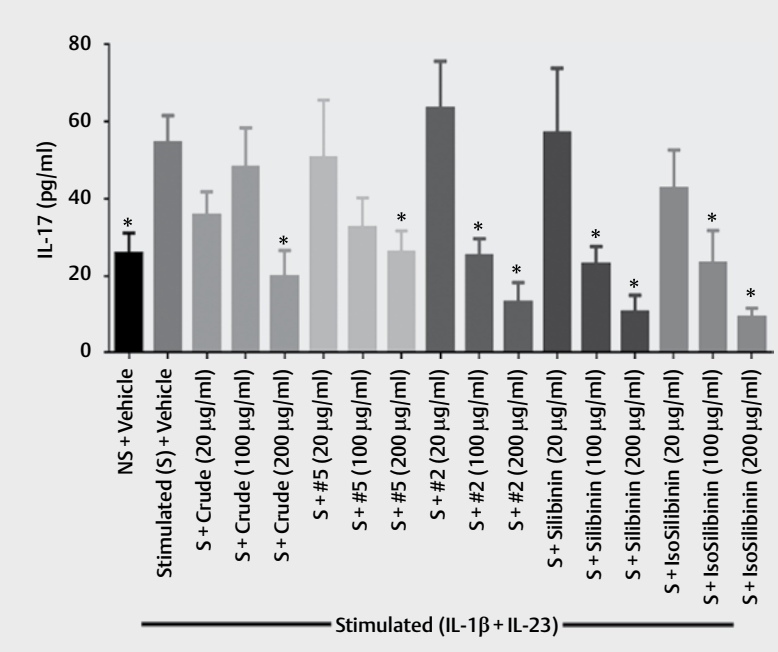

- Fig. 2 Colitis was induced in mice, as described in the Methods section. Six days after the induction of colitis, distal colonic strips of standard size $(4 \mathrm{~mm})$ were cultured for $24 \mathrm{~h}$. Colonic strips were treated with no cytokines, vehicle ( $0.1 \% \mathrm{DMSO})$ plus mouse IL-23 $(10 \mathrm{ng} / \mathrm{mL})$ and mouse IL-1 $\beta(10 \mathrm{ng} / \mathrm{mL})$, or silymarin fractions at 20 , 100 , or $200 \mu \mathrm{g} / \mathrm{mL}+$ dual cytokine treatment. IL-17 secretion was measured from the cell culture media by an appropriate ELISA kit. Values represent the mean \pm SEM of $n=5-22$ per treatment group ( ${ }^{*} \mathrm{p}<0.05$ vs. stimulated + vehicle).

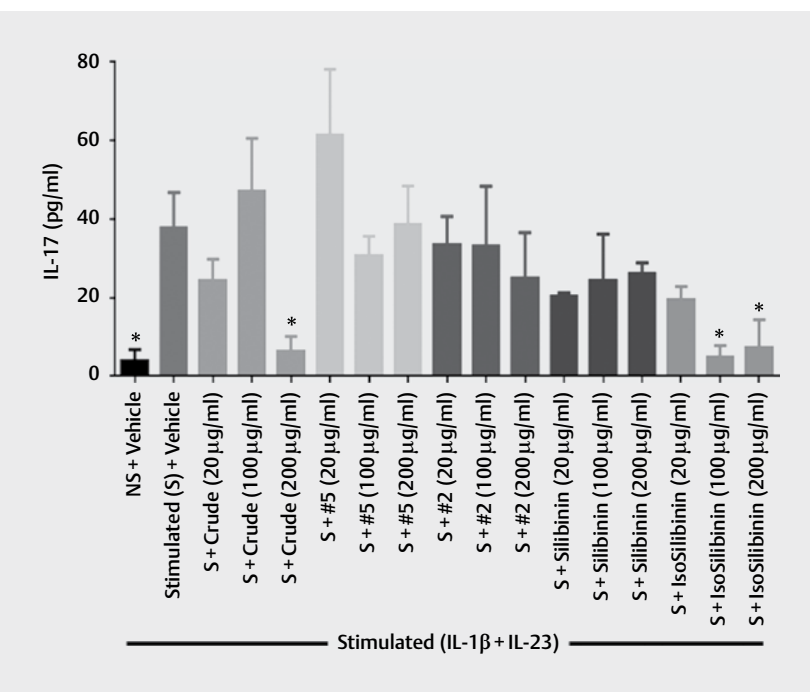

- Fig. 3 Effects of silymarin derivatives on dual cytokine-stimulated IL-17 secretion by colonic strips from water (non-DSS)-treated mice. Six days after the study initiation, multiple distal colonic strips of standard size ( $4 \mathrm{~mm}$ ) were cultured for $24 \mathrm{~h}$. Colonic strips were treated with no cytokines, vehicle $(0.1 \%$ DMSO) plus mouse IL-23 $(10 \mathrm{ng} / \mathrm{mL})$ and mouse IL- $1 \beta(10 \mathrm{ng} / \mathrm{mL})$, or silymarin fractions at 20 , 100 , or $200 \mu \mathrm{g} / \mathrm{mL}+$ dual cytokine treatment. IL-17 secretion was measured from the cell culture media by appropriate ELISA kits. Values represent the mean \pm SEM of $n=2-10$ per treatment group ( ${ }^{*} \mathrm{p}<0.05$ vs. stimulated + vehicle). 


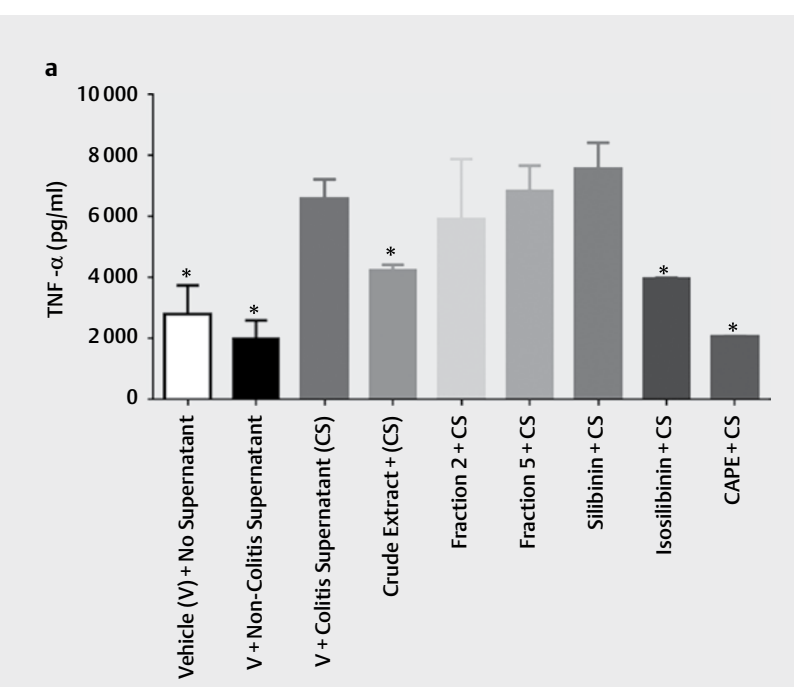

b

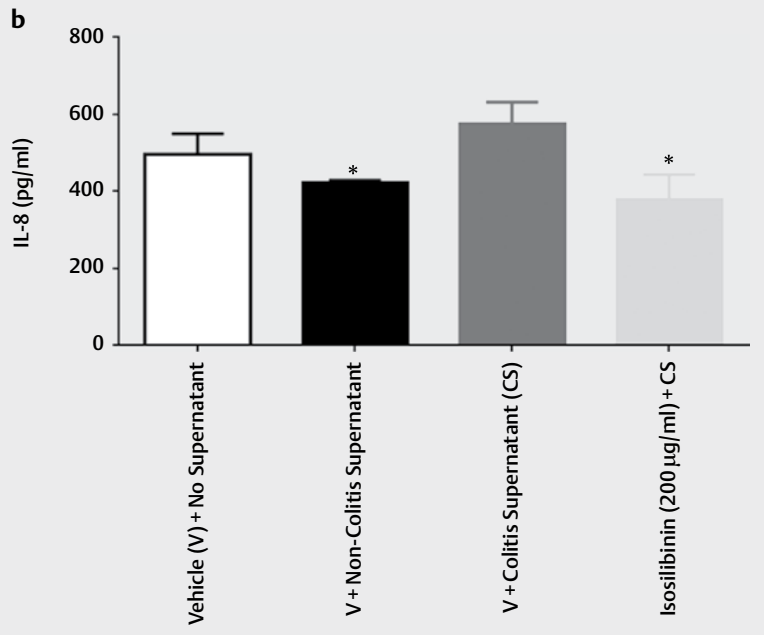

- Fig. 4 a Effects of silymarin derivatives $(200 \mu \mathrm{g} / \mathrm{mL})$ on CS-induced cytokine production by RAW 264.7 cells. TNF- $\alpha$ levels were measured from cell supernatants by a specific ELISA kit. Values represent the mean \pm SEM of $n=2-4$ per treatment group. $\mathbf{b}$ Effects of silymarin derivatives on CS-induced chemokine secretion by HT-29 cells. IL-8 was measured from cell supernatants by a specific ELISA kit. Values represent the mean \pm SEM of $n=3-7$ per treatment group ( ${ }^{*} p<0.05$ vs. vehicle + CS for both panels in the figure).

The theory behind stimulating these cell lines with CS is that unlike typical in vitro experimental conditions [9], the cytokines/ chemokines involved in inflammatory responses of colitis are not singular but multifactorial. Therefore, there is upregulation of multiple cellular signaling pathways and proinflammatory cytokines $[1,16]$. As a result, such CS studies, as well as ex vivo studies, are likely better representative models to test the efficacy of novel compounds prior to in vivo testing. In this regard, preliminary data from our laboratory showed that silymarin fractions could inhibit cytokine secretion from a dual culture system, which involves interactions between macrophage and colonic epithelial cells [18].

Our current data are most likely consistent with the inhibition of a transcription factor(s) by the silymarin-derived fractions/compounds [19]. CAPE (a known NF-kB inhibitor) was effective for inhibiting CS-stimulated TNF- $\alpha$ secretion from macrophages ( $>$ Fig. 4a)
- Table 2 Cell viability data in two cell lines.

\begin{tabular}{|c|c|c|}
\hline \multirow[b]{2}{*}{ Condition $(\mu \mathrm{g} / \mathrm{mL})$} & Raw 264.7 cell line & HT-29 cell line \\
\hline & $\begin{array}{l}\text { Viability } \\
\text { (\% of untreated } \\
\text { control value) }\end{array}$ & $\begin{array}{l}\text { Viability } \\
\text { (\% of untreated } \\
\text { control value) }\end{array}$ \\
\hline Untreated & $100.0 \pm 6.2$ & $100.0 \pm 18.5$ \\
\hline Colitis Supernatant & $100.8 \pm 1.9$ & $84.8 \pm 5.7$ \\
\hline Crude 20 & $121.8 \pm 27.9$ & $92.8 \pm 3.2$ \\
\hline Crude 100 & $95.4 \pm 5.2$ & $127.1 \pm 3.5$ \\
\hline Crude 200 & $101.9 \pm 5.6$ & $93.3 \pm 3.4$ \\
\hline Fraction 220 & $129.7 \pm 6.6$ & $93.9 \pm 4.6$ \\
\hline Fraction 2100 & $131.8 \pm 0.1$ & $94.0 \pm 4.4$ \\
\hline Fraction 2200 & $115.7 \pm 7.8$ & $91.2 \pm 6.7$ \\
\hline Fraction 520 & $122.0 \pm 4.8$ & $88.5 \pm 7.3$ \\
\hline Fraction 5100 & $124.3 \pm 6.0$ & $83.7 \pm 6.3$ \\
\hline Fraction 5200 & $110.8 \pm 12.4$ & $93.6 \pm 14.4$ \\
\hline Silibinin 20 & $103.7 \pm 1.2$ & $97.4 \pm 17.2$ \\
\hline Silibinin 100 & $102.9 \pm 10.8$ & $89.0 \pm 5.3$ \\
\hline Silibinin 200 & $109.6 \pm 4.6$ & $103.2 \pm 1.7$ \\
\hline Isosilibinin 20 & $105.0 \pm 4.5$ & $78.2 \pm 4.1$ \\
\hline Isosilibinin 100 & $112.0 \pm 13.2$ & $85.1 \pm 4.5$ \\
\hline Isosilibinin 200 & $106.4 \pm 5.5$ & $94.1 \pm 1.6$ \\
\hline \multicolumn{3}{|c|}{$\begin{array}{l}\text { Cell viability was determined by the MTT assay. No significant } \\
\text { reductions were found compared to the untreated (control) } \\
\text { condition, which was set as a value of } 100 \% \text { viability. }\end{array}$} \\
\hline
\end{tabular}

[17]. Moreover, previous investigators reported that silibinin treatment inhibited TNF- $\alpha$-induced NF-KB activation in HT29 cells [20]. Therefore, this type of mechanism of action could be the basis for the observed block of cytokine secretion found with flavonoligans in this study $[9,20]$.

Previous studies have demonstrated the efficacy of silymarin (alone or in combination with ursodeoxycholic acid) in a rat TNBS (trinitrobenzene sulfonic acid) colitis model [21, 22]. Moreover, silymarin also showed positive results in a small clinical trial utilizing patients with ulcerative colitis [8]. Our results imply that a promising therapeutic approach for anti-colitis drugs could be with silymarinderived compounds. Specifically, the overall data profile suggests that fraction 2 (containing predominantly isosilibinin), or isosilibinin itself, would be optimal for follow-up in vivo testing in animal models of IBD. Potentially, this research path could lead to further identification of specific silymarin-derived flavonolignans for potential therapeutic use in patients with IBD.

\section{Materials and Methods}

\section{Chemical reagents and reference drugs}

Silymarin, isosilibinin, and CAPE were purchased from Sigma-Aldrich. The MTT assay kit was from ThermoFisher Scientific. All cytokine ELISA kits were obtained from R\&D Systems.

\section{Plant material}

The seeds of milk thistle, used in the investigation to create the crude extract, were obtained from a commercial supplier (San Fran- 
cisco Herb Co.) by Tibebe Woldemariam. The product ID number was 54 (milk thistle seeds).

\section{Extraction and fractionation}

The powdered seeds ( $30 \mathrm{~g}$ ) were extracted into a residue. The residue was then chromatographed on a flash chromatography system. Fractions ( $15 \mathrm{~mL}$ each) were monitored by TLC on silica gel, as described previously [23]. Silymarin fraction compositions were confirmed by LC/MS analyses and characterized employing methods described previously by our laboratory [9]. The individual pure compounds included silibinin A \& B, silychristin, taxifolin, isosilibinin A $\& B$, and apigenin. Fraction 2 contained isosilibinin $A \& B$ (major, 1:3 ratio), silibinin $A \& B$ (1:3 ratio), silychristin (minor), and taxifolin. Fraction 5 contained silibinin $A \& B$ (major 1:1 ratio), silychristin (minor), isosilibinin A \& B (minor, 1:4 ratio), and apigenin [9].

\section{Dextran sulfate sodium colitis model}

We utilized the method described previously by our laboratory [10]. Colitis was induced in male C57BL/6 mice $(n=16)$ by giving $2 \%$ DSS drinking water for a 6 -day period. Control mice $(n=8)$ were given untreated water. During the in-life portion of the study, DAI scores (0-4 severity scale) were recorded on a daily basis [10]. Further, colon lengths were measured on study day 6 . The associated animal protocol was approved by IACUC's at California Northstate University (Elk Grove, CA; Protocol \# is CNU0001, with an approval date of 12/18/2015) and Antibodies Incorporated (Davis, CA; Protocol \# is 0416-1, with an approval date of $4 / 28 / 2016$ ).

\section{Ex vivo colonic strip model}

Employing a 24-h colonic culture system, the ex vivo effects of crude silymarin extract, two different silymarin fractions, as well as commercially derived silibinin and isosilibinin $(20,100$, and $200 \mu \mathrm{g} / \mathrm{mL})$, were examined [10]. Colonic strips obtained from mice with/without DSS-induced colitis were used, and the secretion of MIP-2, TNF- $\alpha$, and IL-17 in cell culture media was determined using appropriate ELISA kits.

\section{Murine macrophage (RAW 264.7) cell line}

One hour prior to stimulation of murine-derived macrophages, crude silymarin extract, two different silymarin fractions, commercially derived silibinin and isosilibinin $(200 \mu \mathrm{g} / \mathrm{mL})$ as well as CAPE (positive control drug) were added to the cell culture. RAW 264.7 murine macrophages were then stimulated with the colitis supernatant $(50 \mu \mathrm{L})$. The colitis supernatant was obtained from the vehicle/DSS group using the colonic strip model. After $4 \mathrm{~h}$, the cell culture supernatant was collected for determination of TNF- $\alpha$ using an appropriate ELISA kit. Cell viability was determined by the MTT assay.

\section{Colonic epithelial (HT-29) cell line}

One hour prior to stimulation of human colonic epithelial cells, isosilibinin was added to the cell culture system at a concentration of $200 \mu \mathrm{g} / \mathrm{mL}$. HT-29 colonocytes were then stimulated with the colitis supernatant $(50 \mu \mathrm{L})$. Once again, the colitis supernatant was obtained from the vehicle/DSS group using the colonic strip model. After $4 \mathrm{~h}$, the cell culture supernatant was collected for determination of IL-8 using an ELISA kit. Cell viability was assessed by the MTT assay.

\section{Statistical analyses}

All statistics were done with GraphPad Prism. Testing for normal distribution of the data was done by the D'Agostino \& Pearson omnibus normality test. Student's t-test for unpaired data was utilized for analyses of the murine colitis parameters. This statistical method was also used to analyze the in vitro cell culture data. If ANOVA testing showed a difference between treatment groups means, we then utilized Sidak's multiple comparison tests for analyzing the ex vivo colonic strip data. Statistical significance was attained if the $p$ value was $<0.05$ for the analyses performed.

\section{Acknowledgements}

We acknowledge that Leo Fitzpatrick and Ella Mokrushin contributed equally to the first authorship of this manuscript. We would also like to acknowledge the research personnel at Antibodies Incorporated (Davis, CA) for their help with the animal husbandry associated with our study.

\section{Conflict of Interest}

The authors declare no conflict of interest.

\section{References}

[1] Fitzpatrick LR. Novel pharmacological approaches for inflammatory bowel disease: Targeting key intracellular pathways and the IL-23/IL-17 axis. Int J Inflam 2012; 2012: 389404

[2] Zhu H], Brinda B], Chavin KD, Bernstein H], Patrick KS, Markowitz JS. An assessment of pharmacokinetics and antioxidant activity of free silymarin flavonoligans in health volunteers: A dose escalation study. Drug Metab Dispos 2013; 41: 1479-1485

[3] Biijak M. Silybin, a major bioactive component of milk thistle (Silybum marianum L Gaernt.)-chemistry, bioavailability and metabolism. Molecules 2017; 22: E1942

[4] Abenavoli L, Capasso R, Milic N, Capasso F. Milk thistle in liver diseases: Past, present, future. Phytother Res 2010; 24: 1423-1432

[5] Neha Jaggi AS, Singh N. Silymarin and Its Role in Chronic Diseases. Adv Exp Med Biol 2016; 929: 25-44

[6] Polachi N, Bai G, Li T, Chu Y, Wang X, Li S, Gu N, Wu J, Li W, Zhang Y, Zhou $\mathrm{S}$, Sun $\mathrm{H}$, Liu C. Modulatory effects of silibinin in various cell signaling pathways against liver disorders and cancer. Eur J Med Chem 2016; 123: 577-595

[7] Scambia G, De Vincenzo R, Ranelletti FO, Panici PB, Ferrandina G, D'Agostino G, Fattorossi A, Bombardelli E, Mancuso S. Antiproliferative effect of silybin on gynaecological malignancies: Synergism with cisplatin and doxorubicin. Eur J Cancer 1996; 32A: 877-882

[8] Rastegarpanah M, Malekzadeh R, Vahedi H, Mohammadi M, Elahi E, Chaharmahali M, Safarnavadeh T, Abdollahi M. A randomized, double blinded, placebo-controlled clinical trial of silymarin in ulcerative colitis. Chin J Integr Med 2015; 21: 902-906

[9] Talbott G, Woldemariam T, Fitzpatrick LR. Effects of silymarin fractions on pro-inflammatory cytokine secretion from macrophage and colonic epithelial cell lines. Pharm Pharmacol Int J 2017; 5: 00128

[10] Fitzpatrick LR, Stonesifer E, Small JS, Liby KT. The synthetic triterpenoid (CDDO-Im) inhibits STAT3, as well as IL-17, and improves DSS-induced colitis in mice. Inflammopharmacology 2014; 22: 341-349 
[11] Ohstuka Y, Sanderson IR. Dextran sulfate-sodium induced inflammation is enhanced by intestinal epithelial cell chemokine expression in mice. Pediatr Res 2003; 53: 143-147

[12] Kleinscheck MA, Boniface K, Sadevoka S, Grein J, Murphy EE, Turner SP, Raskin L, Desai B, Faubion WA, de Waal Malefyt R, Pierce RH, McClanahan T, Kastelein RA. Circulating and gut resident human Th17 cells express CD161 and promote intestinal inflammation. J Exp Med 2009; 206: 525-534

[13] Coccia M, Harrison OJ, Schiering C, Asquith M], Becher B, Powrie F, Maloy KJ. IL-1 $\beta$ mediates chronic intestinal inflammation by promoting the accumulation of IL-17A secreting innate lymphoid cells and CD4(+) Th17cells. J Exp Med 2012; 209: 1595-1609

[14] Withers DR, Hepworth MR, Wang X, Mackley EC, Halford EE, Dutton EE, Marriott CL, Brucklacher-Waldert V, Veldhoen M, Kelsen J, Baldassano RN, Sonnenberg GF. Transient inhibition of ROR- $Y$ T therapeutically limits intestinal inflammation by reducing $\mathrm{TH} 17$ cells and preserving group 3 innate lymphoid cells. Nat Med 2016; 22: 319-323

[15] Fitzpatrick LR, Talbott G, Buhr CA, Alton G, Zapf J. Ex vivo effects of ROR-gamma $T$ inhibitors on proinflammatory cytokine secretion from colonic strips of mice with DSS-induced colitis. Gastroenterology 2018; 154: S1007-S1008

[16] Fitzpatrick LR, Wang J, Le T. In vitro and in vivo effects of gliotoxin, a fungal metabolite: efficacy against dextran sodium sulfate-induced colitis in rats. Dig Dis Sci 2000; 45: 2327-2336
[17] Fitzpatrick LR, Wang T, Le T. Caffeic acid phenethyl ester, an inhibitor of nuclear factor-kappaB, attenuates bacterial peptidoglycan polysaccharide-induced colitis in rats. J Pharmacol Exp Ther 2001; 299: 915-920

[18] Fitzpatrick LR, Talbott G, Woldemariam T. Effects of silymarin fractions on pro-inflammatory cytokine secretion from macrophage and colonic epithelial cell lines. Gastroenterology 2016; 150: S376-S377

[19] Surai PF. Silymarin as a Natural Antioxidant: An Overview of the Current Evidence and Perspective. Antioxidants (Basel) 2015; 4: 204-247

[20] Raina K, Agarwal C, Agarwal R. Effect of silibinin in human colorectal cancer cells: targeting the activation of NF- $\mathrm{KB}$ signaling. Mol Carcinog 2013; 52: 195-206

[21] Esmaily H, Hosseini-Tabatabaei A, Rahimian R, Khorasani R, Baeeri M, Barazesh-Morgani A, Yesa N, Khademi Y, Abdollahi M. On the benefits of silymarin in murine colitis by improving balance of destructive cytokines and reduction of toxic stress in the bowel cells. Cent Eur J Biol 2009; 4: 204-213

[22] Esmaily H, Vaziri-Bami A, Miroliaee AE, Baeeri M, Abdollahi M. The correlation between NF-KB inhibition and disease activity by coadministration of silibinin and ursodeoxycholic acid in experimental colitis. Fundam Clin Pharmacol 2011; 25: 723-733

[23] Woldemariam TZ, Malekakhlagh A, Bett C, Pearson D. Evaluation of the antitumor activity of selected herbs and spices. J Pharm Sci Pharmacol 2014; 1: 296-303 